\title{
Antibiotic Susceptibility Pattern and Multiple Antibiotic Resistance Index of Salmonella enterica Isolates from Horses in Bikaner
}

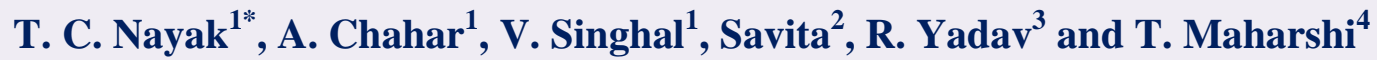

${ }^{1}$ Department of Epidemiology and Preventive Veterinary Medicine, ${ }^{4}$ Department of Clinical Veterinary Medicine, Ethics and Jurisprudence, College of Veterinary and Animal Science, Rajasthan University of Veterinary and Animal Sciences, Bikaner, Rajasthan, India ${ }^{2}$ Veterinary Surgeon, Animal Husbandry \& Dairying Department, Panchkula (Haryana) India ${ }^{3}$ Animal Health Specialist (Vety. Medicine), Lala Lajpat Rai University of Veterinary \& Animal Sciences, Hisar (Haryana) India

*Corresponding author

\section{A B S T R A C T}

Keywords

Horses, Salmonella entrica,

Antibiogram and Multiple Antibiotic Resistance Index

Article Info

Accepted:

12 January 2021

Available Online:

10 February 2021
In present study, 160 horses were screened for enteric Salmonella and their antimicrobial resistance pattern in Bikaner. Presence of InvA gene in faecal samples was used as marker for Salmonella shedding. Antimicrobial resistance analysis against 10 different antibiotics was done on 11 isolates of Salmonella enterica. The results revealed that the Salmonella isolates were sensitive to ceftriaxone + tazobactum (100 per cent), cefoperazone (81.81 per cent), and cefuroxime (81.81 per cent). All (100 per cent) the strains were found resistant to penicillin-G and 72.73 per cent isolates were resistant to tetracycline. Six isolates exhibited multiple drug resistance against 3 to 9 antibiotics with Multiple Antibiotic index ranging from 0.10 to 0.90 . MAR, index of 0.70 was found in maximum number of isolates (3) which were resistant to seven different antimicrobials.

\section{Introduction}

Salmonellosis is caused by enteric or systemic infection with bacteria of Salmonella spp. Horses can be affected with salmonellosis without showing any apparent clinical signs and symptoms, and transient shedding of organisms in faeces. Such latent carriers can turn into a clinical case under stress condition. Case fatality rate of salmonellosis in equines is up to 60 per cent (Constable et al., 2017).
Horses are at high risk of nosocomial salmonellosis infection in veterinary teaching hospitals because of exposure to a common source of Salmonella organisms (e.g., contaminated feed) or by lateral transmission from infected animals (Kim et al., 2001). In some instances, these facilities have been forced to close temporarily ( $\geq 3$ months) because of serious outbreaks of clinical disease caused by Salmonella infection in horses (Ernst et al., 2004). In the past few 
decades, emergence of antibiotic resistance among different species of bacteria is on the rise (Davies and Davies, 2010). The problem is compounded when it occurs in pathogenic bacteria like Salmonella enterica having public health significance. Bikaner city have a good equine population and in past no study have been carried out to know the status of antibiotic resistance against salmonellosis in horses in this area. Therefore, the present study was conducted to know the antibiogram profile of Salmonella enterica isolated from horses of Bikaner to evaluate and monitor the extent of antibiotic resistance in the isolates of this region. Multiple Antibiotic Resistance (MAR) index was also calculated which has been shown to be a cost effective and valid method of bacteria source tracking.

\section{Materials and Methods}

\section{Collection of samples}

Rectal swabs were taken in triplicate over a period of 24 hours by using transport swab containing cary-blair medium from 160 horses belonged to different stud farms and veterinary hospitals of Bikaner area in Rajasthan state.

\section{Sample processing}

Salmonella were detected using selective enrichment faecal cultures. For this, faecal swab samples were used to inoculate faecal material into $10 \mathrm{ml}$ of mannitol selenite broth, which were incubated overnight at $37{ }^{\circ} \mathrm{C}$. The swabs were then streaked onto xylose lysine deoxycholate (XLD) agar plates and incubated at $37^{\circ} \mathrm{C}$ for $18-24$ hours for isolation and identification of Salmonella pure colonies. On XLD agar plates colony morphology of Salmonella was appeared as red colonies with black centres (Plate. 1), and on microscopic examination gram-negative, rod-shaped bacterial cells after gram's staining. For confirmatory diagnosis isolated pure colonies of Salmonella were further incubated for 24 hours at $37{ }^{\circ} \mathrm{C}$ in nutrient broth for DNA extraction and characterization by highly conserved 457 bp nucleotide sequence within the invasion gene (invA) of Salmonella spp. by polymerase chain reaction (PCR) assay (Plate. 2).

\section{In-vitro chemotherapeutic sensitivity}

In the present investigation, all Salmonella spp. isolates were subjected to resistotyping with 10 different antibiotics. In-vitro antibiotic sensitivity pattern of the isolates were determined by disc diffusion method of Bauer et al., (1966). The Salmonella spp. isolates were tested against commonly used antibiotics viz. cefoperazine (CPZ), cefuroxime (CXM), ceftriaxone/tazobactum (CIT), penicillin (P), amoxycillin/clavulanic acid (AMC), ampicillin/sulbactum (A/S), streptomycin (S), erythromycin (E), tetracycline (TE) and gentamicin (GEN).

Test bacteria broth culture swabbed on Muller Hinton agar plates with sterile cotton swabs. When broth culture was dried, the antibiotic discs were placed with the help of automatic disc dispenser in front of flame. These petri dishes were incubated for 15-20 hours and observed for zone of inhibition. Diameters of zone of inhibition $(\mathrm{mm})$ were observed and results were interpreted as sensitive, intermediate and resistant based on the CLSI guidelines.

\section{MAR (Multiple Antibiotic Resistance) Index Study}

The MAR Index of an isolate is defined as $a / b$, where ' $a$ ' represents the number of antibiotics to which the isolate was resistant and ' $b$ ' represents the number of antibiotics to which the isolate was subjected (Jayaraman et al., 2012). 
Identification of MDR (Multi Drug Resistance)

Multi Drug Resistance is defined as resistance to more than two classes of antibiotics among all the tested antibiotics. The Multi Drug Resistance (MDR) characters of the isolates were identified by observing the resistance pattern of the isolates to the antibiotics.

\section{Results and Discussion}

The detailed results of antibiotic sensitivity test of Salmonella isolates are given in table 1 . The results of antibiogram showed that all (100 per cent) of the isolates were resistant to
penicillin-G followed by tetracycline (72.73 per cent), amoxycillin + clavulanic (54.55 per cent), gentamicin (45.45 per cent), ampicillin + sulbactum (36.36 per cent), erythromycin (36.36 per cent), streptomycin (36.36 per cent), cefoperazone (9.09 per cent) and cefuroxime (9.09 per cent) (Fig. 1).

Ceftriaxone + tazobactum were found most effective against Salmonella spp. during invitro study with sensitivity in all isolates (100 per cent). Cefoperazone and cefuroxime were found reasonably effective as both the antibiotics showed 81.81 per cent sensitive against Salmonella isolates.

Table.1 Antibiotic sensitivity patterns of Salmonella isolates of horse origin

\begin{tabular}{|c|c|c|c|c|}
\hline S.No. & Antibiotics & Sensitive & Intermediate & Resistant \\
\hline $\mathbf{1 .}$ & Ceftriaxone + tazobactum & $11(100.00)$ & $00(00.00)$ & $00(00.00)$ \\
\hline $\mathbf{2 .}$ & Cefoperazone & $09(81.81)$ & $01(09.09)$ & $01(09.09)$ \\
\hline $\mathbf{3 .}$ & Ampicillin + sulbactum & $06(54.54)$ & $01(09.09)$ & $04(36.36)$ \\
\hline $\mathbf{4 .}$ & Cefuroxime & $09(81.81)$ & $01(09.09)$ & $01(09.09)$ \\
\hline $\mathbf{5 .}$ & Streptomycin & $05(45.45)$ & $02(18.18)$ & $04(36.36)$ \\
\hline $\mathbf{6 .}$ & Amoxycillin + clavulanic & $02(18.18)$ & $03(27.27)$ & $06(54.54)$ \\
\hline $\mathbf{7 .}$ & Penicillin-G & $00(00.00)$ & $00(00.00)$ & $11(100.00)$ \\
\hline $\mathbf{8 .}$ & Tetracycline & $00(00.00)$ & $03(27.27)$ & $08(72.73)$ \\
\hline $\mathbf{9 .}$ & Erythromycin & $04(36.36)$ & $03(27.27)$ & $04(36.36)$ \\
\hline $\mathbf{1 0}$ & Gentamicin & $03(27.27)$ & $03(18.18)$ & $05(45.45)$ \\
\hline
\end{tabular}

Table.2 Multiple Antibiotic Resistance index of Salmonella enterica isolates

\begin{tabular}{|c|l|c|c|}
\hline S.No. & isolates & $\begin{array}{c}\text { No.of antibiotics to which } \\
\text { isolate is resistant(a) }\end{array}$ & MAR index=a/b \\
\hline $\mathbf{1}$ & Salmonella enterica & 1 & $1 / 10=0.10$ \\
\hline $\mathbf{2}$ & Salmonella enterica & 1 & $1 / 10=0.10$ \\
\hline $\mathbf{3}$ & Salmonella enterica & 1 & $1 / 10=0.10$ \\
\hline $\mathbf{4}$ & Salmonella enterica & 2 & $2 / 10=0.20$ \\
\hline $\mathbf{5}$ & Salmonella enterica & 2 & $2 / 10=0.20$ \\
\hline $\mathbf{6}$ & Salmonella enterica & 3 & $3 / 10=0.30$ \\
\hline $\mathbf{7}$ & Salmonella enterica & 4 & $4 / 10=0.40$ \\
\hline $\mathbf{8}$ & Salmonella enterica & 7 & $7 / 10=0.70$ \\
\hline $\mathbf{9}$ & Salmonella enterica & 7 & $7 / 10=0.70$ \\
\hline $\mathbf{1 0}$ & Salmonella enterica & 7 & $7 / 10=0.70$ \\
\hline $\mathbf{1 1}$ & Salmonella enterica & 9 & $9 / 10=0.90$ \\
\hline
\end{tabular}


Fig.1 Percentage antibiotic sensitivity patterns of Salmonella isolates of horse origin

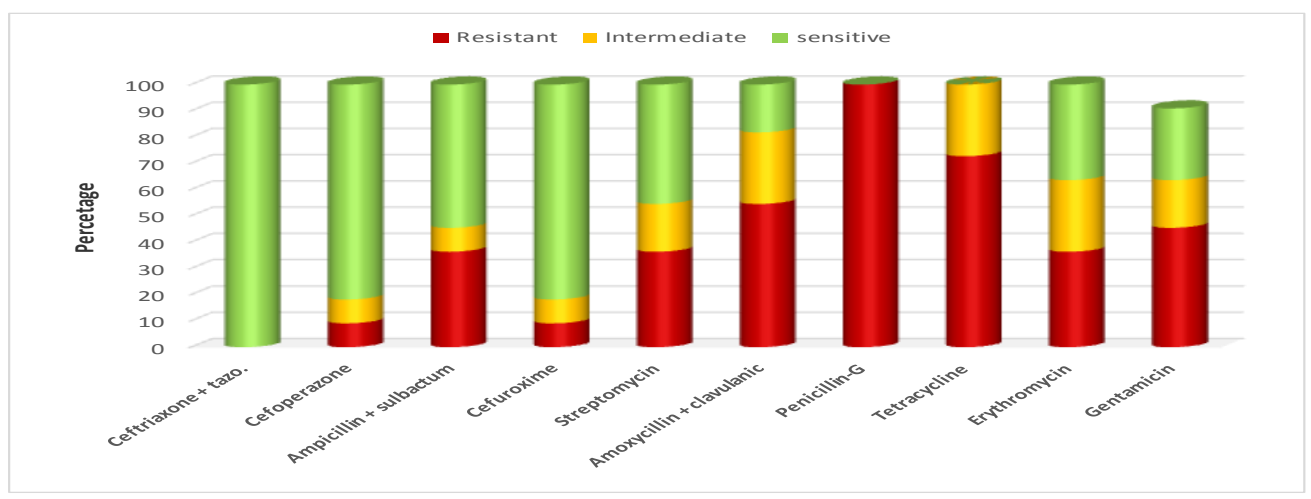

Plate.1 Salmonella species: red colonies, with black centers on XLD agar

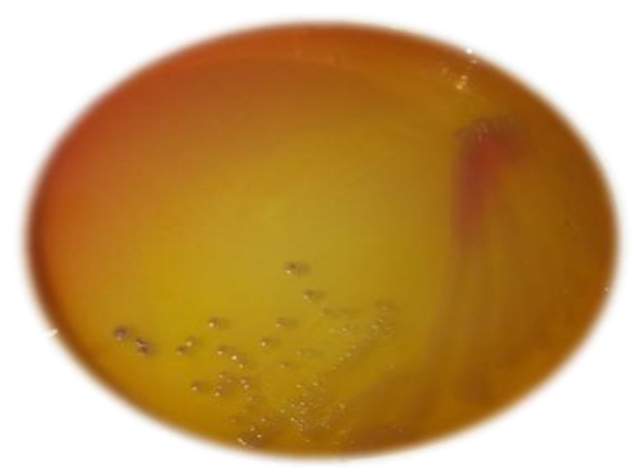

Plate.2 Amplification of a 457bp fragment of Salmonella genus specific InvA gene in apparently healthy horses

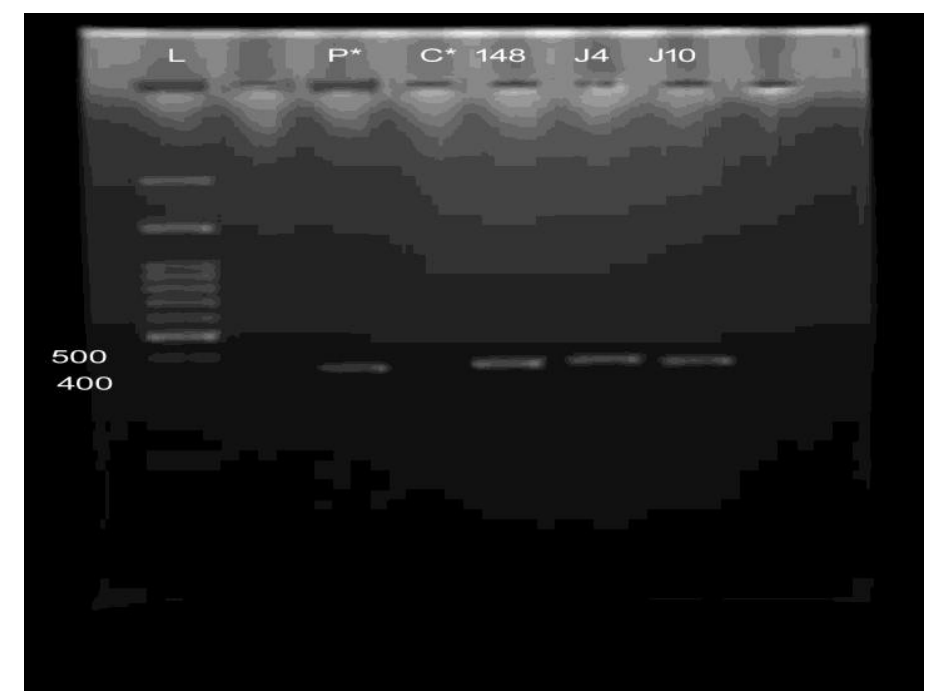

$\left(\mathrm{P}^{*}=+\mathrm{ve}\right.$ Control; $\mathrm{C}^{*}=-$-ve Control; $\mathrm{L}=$ Ladder $)$ 
These result are comparable to the findings of earlier workers who determined different resistance patterns among Salmonella strains of equine origin and other animals in India (Agarwal et al., 2004; Chandra et al., 2006; Gaind, 2007; Singh et al., 2007; Singh et al., 2009; Khan et al., 2015; Kalambhe et al., 2016; Kulkarni et al., 2019), might be attributable to change in antimicrobial drug therapy in equids. Growing resistance towards antimicrobial drugs has been prevalent worldwide among members of Enterobacteriaceae from animal origin especially in Salmonella sp. The high resistance to penicillin-G and tetracycline antibiotics might be due to over use of drugs or transmission of resistant strains of Salmonella from other sources i.e. human, other animals and environment etc. in the absence of hygienic practices.

Multiple drug resistance was recorded in 6 (54.54 per cent) out of the 11 isolates which showed resistance against 3 to 9 antibiotics (table 2). The multiple drug resistance Index calculated ranged from 0.10 to 0.90 with 0.70 being the predominant MAR index in 3 isolates (table 2).

Multiple antibiotic resistance (MAR) has been attributed to the presence of plasmids which contain one or more resistance genes, each encoding a single antibiotic resistance phenotype (Daini et al., 2005). Findings of the present study were in accordance with Singh et al., (2012), Khan et al., (2015) and Kalambhe et al., (2016) who also reported multiple drug resistance against 3 to 9 antimicrobials in several Salmonella isolates of animal and human origin in India. Emergence of multiple drug resistant Salmonella strains has often been held responsible for frequently occurring outbreaks and hyper-endemicity of salmonellosis in India (Singh et al., 2006). India has become home for multiple drug resistant strains of different Salmonella serotypes. The phenomena namely the localization of resistance genes on conjugative plasmids, cointegrate formation which gave rise to new plasmids and the localization of resistance genes on transposes has led to the efficient spread of multiple drug resistance in Salmonella (Helmuth, 2000).

In conclusion the present study revealed that ceftriaxone + tazobactum is the best effective antibiotic to treat Salmonella infection in horses. The susceptibility pattern of Salmonella isolates of horses from different sources of Bikaner region showed that they were highly resistant to penicillin-G and tetracycline.

\section{References}

Agarwal, M., Singh, B.R., Santoshi, M.C., Singh, V.P., Chandra, M. 2004. A study on biotyping, bacteriocin typing and drug resistogram of Salmonella Paratyphi B isolates from animals, their products and environment. Indian Journal of Comparative Microbiology, Immunology and Infectious Diseases, 24: 159-164.

Bauer, A.W., Kirby, W.M., Sherris, J.C. and Turck, M. 1966. Antibiotic susceptibility testing by a standardized single disc method. American Journal of Clinical Pathology, 45: 493496.

Chandra, M., Singh, B.R., Shankar, H., Agarwal, M., Agarwal, R.K., Sharma, G. 2006. Study on prevalence of Salmonella infection in goats. Small Ruminant Research, 65: 24-30.

Constable, P.D., Hinchcliff, K.W., Done, S.H., and Grünberg, W. 2017. Veterinary medicine: A textbook of the diseases of cattle, sheep, pigs, goats and horses. $11^{\text {th }}$ edn., Saunders publication co., Oxford, London. 
Daini, O.A., Ogbolu, O.D. and Ogunledun A. 2005. Quinolone resistance and Rplasmids of some Gram negative enteric bacilli. African Journal of Clinical and Experimental Microbiology, 6(1): 1420.

Davies, J., and Davies, D. 2010. Origins and Evolution of Antibiotic Resistance. Microbiology and Molecular Biology Reviews, 74(3): 417-433.

Ernst, N.S., Hernandez, J.A., MacKay, R.J., Brown, M.P., Gaskin, J.M., Nguyen, A.D. and Addison, I.R. 2004. Risk factors associated with fecal Salmonella shedding among hospitalized horses with signs of gastrointestinal tract disease. Journal of the American Veterinary Medical Association, 225(2): 275-281.

Gaind, R. 2007. Molecular epidemiology and characteristics of MDR $S$. enteric serotype Typhi in India. Proceedings Symposium on Enteric Fever and OtherEnteric Infections,Safdarjang Hospital, NewDelhi, March 24, 2007.

Helmuth, R. 2000. Antibiotic resistance in Salmonella. In: Wray, C. and Wray, A. (eds) Salmonella in Domestic Animals. 2000. CABI publishing, New York, USA, pp. $89-101$.

Jayaraman, S.K., Manoharan, M., Ilanchezian, S., Sekher R. and Sathyamurthy. 2012. Plasmid analysis and prevalence of Multidrug resistant Staphylococcus aureus reservoirs in Chennai city, India. Asian Journal of Pharmacy and Life Science, 2(2): 2231 $-4423$.

Kalambhe, D.G., Zade, N.N., Chaudhari, S.P., Shinde, S.V., Khan, W., and Patil, A.R. 2016. Isolation, antibiogram and pathogenicity of Salmonella spp. recovered from slaughtered food animals in Nagpur region of Central India. Veterinary world, 9(2): 176.

Khan, J.A., Mir, I.A., Soni, S.S., and
Maherchandani, S. 2015. Antibiogram and multiple antibiotic resistance index of Salmonella enterica isolates from poultry. Journal of Pure and Applied Microbiology, 9(3): 2495-2501.

Kim, L.M., Morley, P.S., Traub-Dargatz, J.L., Salman, M.D. and Gentry-Weeks, C. 2001. Factors associated with Salmonella shedding among equine colic patients at a veterinary teaching hospital. Journal of American Veteterinary Medical Association, 218(5): 740-748.

Kulkarni, M.B., Deshmukh, S.S., Agiwale, S.M. and Awandkar, S.P. 2019. Antibiogram of Pathogens from Nasal Affections in Equine. Intas Polivet, 20(2): 385-389.

Singh, B.R., Babu, N., Jyoti, J., Shankar, H., Vijo, T.V., Agrawal, R.K., and Teewari, A. 2007. Prevalence of multi-drugresistant Salmonella in equids maintained by low income individuals and on designated equine farms in India. Journal of Equine Veterinary Science, 27(6): 266-276.

Singh, B.R., Jyoti, J., Chandra, M., Babu, N., and Sharma, G. 2009. Drug resistance patterns of Salmonella isolates of equine origin from India. The Journal of Infection in Developing Countries, 3(02): 141-147.

Singh, B.R., Singh, M., Singh, P., Babu, N., Chandra, M., Agarwal, R.K. 2006. Prevalence of multidrug-resistant Salmonella on ready-to-eat betel leaves (Paan) and in water used for soaking betel leaves in North Indian cities. The Journal of Food Protection, 69(2): 288-92.

Singh, S., Agarwal, R.K., Tiwari, S.C., Singh, H. 2012. Antibiotic resistance pattern among the Salmonella isolated from human, animal and meat in India. Tropical Animal Health and Production, 44(3): 665-74. 


\section{How to cite this article:}

Nayak, T. C., A. Chahar, V. Singhal, Savita, R. Yadav and Maharshi, T. 2021. Antibiotic Susceptibility Pattern and Multiple Antibiotic Resistance Index of Salmonella enterica Isolates from Horses in Bikaner. Int.J.Curr.Microbiol.App.Sci. 10(02): 134-140. doi: https://doi.org/10.20546/ijcmas.2021.1002.017 